\title{
Erratum to: A validation study of the use of mathematical knowledge for teaching measures in Ireland
}

\author{
Seán Delaney
}

Published online: 8 May 2012

(c) FIZ Karlsruhe 2012

Erratum to: ZDM Mathematics Education

DOI 10.1007/s11858-012-0382-5

In the article the scores of Hilda and Sheila are incorrectly labeled in Fig. 3. The names should be switched with one another in order to correctly correspond to the related information in Table 7, which is accurate. The correct version of Fig. 3 is given below.

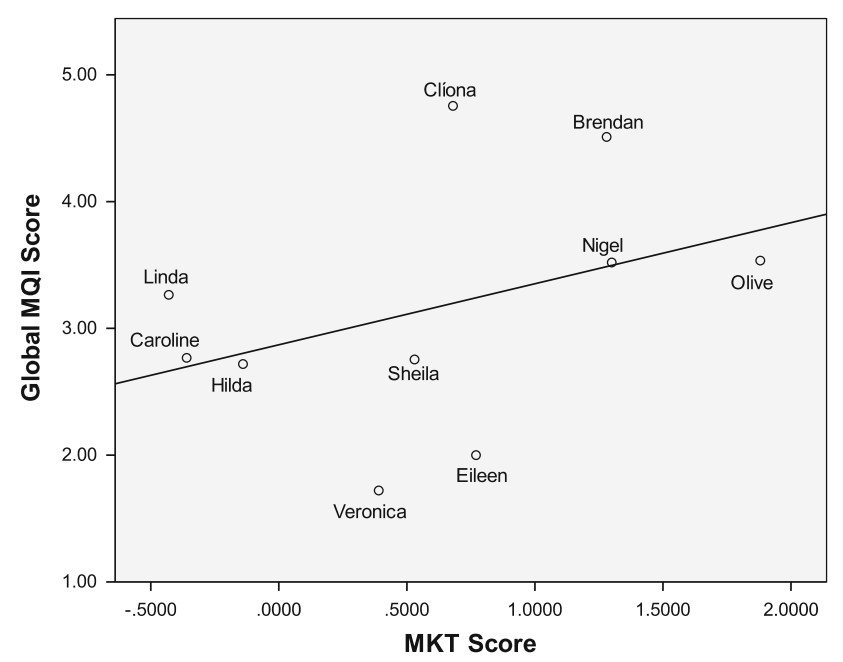

Fig. 3 A regression line fitted to a scatterplot of teachers' scores on MKT and MQI

The online version of the original article can be found under doi:10.1007/s11858-012-0382-5.

S. Delaney $(\bowtie)$

Coláiste Mhuire, Marino Institute of Education, Dublin, Ireland

e-mail: sean.delaney@mie.ie 